\title{
INTERAÇÕES DISCURSIVAS EM AULAS DE QUÍMICA AO REDOR DE ATIVIDADES EXPERIMENTAIS: UMA ANÁLISE SOCIOLÓGICA ${ }^{1}$
}

\begin{abstract}
RESUMO: Este artigo apresenta os resultados de uma pesquisa realizada com dois professores de química do ensino médio. Com base na observação e no registro das aulas, analisamos as interações verbais entre professores e alunos em torno da definição das atividades experimentais, utilizando, para isso, uma perspectiva oriunda da sociologia da educação desenvolvida por Basil Bernstein, o que nos permitiu contrastar as situações de ensino originadas em contextos escolares socialmente diferentes. Os resultados obtidos nos indicaram quais práticas pedagógicas se mostraram mais favoráveis à intervenção dos alunos e à produção por estes das tarefas solicitadas. Percebemos que os alunos submetidos à prática cuja professora exerce maior controle sobre a comunicação tiveram menos oportunidade de intervir nas atividades e uma instrução sobre a tarefa mais pobre que aqueles que possuíam maior liberdade nas interações com o professor. Palavras-chave: Interações discursivas. Prática pedagógica. Atividades experimentais.
\end{abstract}

\section{DISCURSIVE INTERACTIONS IN CHEMSTRY CLASSROOMS RELATED TO EXPERIMENTAL ACTIVITIES: A SOCIOLOGICAL ANALYSIS}

ABSTRACT: This article presents the results of a research done with two chemistry teachers of secondary schools. Based on observation and on registering classes, we analyzed verbal interactions amongst teachers and students around experimental activities and the tasks that followed them. We used a sociologic perspective from Basil Bernstein to analyze our data, which allowed us to contrast the teaching in two socially different school contexts. The results pointed out those pedagogic practices were most favorable to intervention of students and to production of the requested tasks. We noticed that the students submitted to a practice which teacher has a greatest control over communication had fewer chances to intervene during the activities and also a poorest instruction than students that had a major freedom during interactions with their teacher.

Keywords: Discursive interactions. Pedagogic practice. Experimental activities.

DOI - http://dx.doi.org/10.1590/1983-21172014160311

\author{
Bruno Ferreira dos Santos * \\ Karina Novaes dos Santos ** \\ Eliana Sardinha da Silva ***
}

\footnotetext{
* Doutor em Ciências Sociais e Humanas (Universidade Nacional de Quilmes, Argentina). Professor do Departamento de Química e Exatas da Universidade Estadual do Sudoeste da Bahia (UESB). E-mail: bf-santos@uol.com.br

* * Mestranda em Educação Científica e Formação de Professores, Universidade Estadual do Sudoeste da Bahia (UESB). E-mail: karina_novaes@ymail.com

*** Mestranda em Educação Científica e Formação de Professores, Universidade Estadual do Sudoeste da Bahia (UESB). Professora do Colégio Estadual Professor Milton Santos. E-mail: Iyufroes@hotmail.com
} 


\section{INTRODUÇÃO}

Passados mais de 40 anos que, de acordo com Coll e Edwards (1998), o "discurso educativo tornou-se um foco prioritário de atenção para aqueles que pesquisam os processos escolares de ensino e aprendizagem” (p. 9), temos a sensação de que muito ainda deve ser realizado para obtermos uma tão desejada teoria sobre a prática educativa, a qual leve em conta aspectos do discurso educativo. No campo específico da pesquisa em educação em ciências, 24 anos nos separam da publicação do livro Talking science: language, learning and values, de Jay Lemke (LEMKE, 1997), um marco de referência para os estudos sobre o discurso nas aulas de ciência (KELLY, 2008). Desde então, a linguagem e as interações discursivas tornaram-se dois dos focos principais da pesquisa em nossa área. Entretanto, como já foi dito, parece haver muito ainda por percorrer, e um dos pontos débeis da agenda dessa pesquisa vem a ser a formação de professores. Segundo Gregory Kelly (2008), ainda existe pouca pesquisa produzida relacionando o discurso e a formação de professores, e os resultados já consensuados da investigação ainda não foram capazes de influenciar as práticas de ensino e a aprendizagem em sala de aula.

Talvez parte dessa debilidade possa ser explicada considerando a multiplicidade de abordagens teóricas e metodológicas empregadas nos estudos sobre a linguagem e as interações discursivas. A esse respeito, Coll e Sánchez (2008) argumentam que essa situação é esperada, levando em conta que esse tipo de investigação encontra-se ainda em sua primeira fase de desenvolvimento. Com isso, o diálogo e a compreensão mútua dos resultados de pesquisas originadas por marcos teórico-metodológicos tão distintos entre si têm sido comprometidos. A introdução das teorias socioculturais sobre a aprendizagem na pesquisa em torno dos processos discursivos em educação em ciências, por sua parte, ainda não produziu conhecimento sobre como criar novos contextos educacionais para o ensino e a aprendizagem baseados nessas teorias (KELLY, 2008).

Esse descompasso entre a pesquisa e seus resultados e a prática educativa não é um privilégio da investigação sobre a linguagem e as interações discursivas, muito embora a proposição de novos modelos para o ensino baseados em conhecimento gerado pela pesquisa acadêmica seja, de certo modo, desencorajada em função do desejo de relações mais horizontais entre pesquisadores e docentes. Essa reorientação nas relações entre pesquisadores e docentes tem a ver, segundo Coll e Sánchez, com a "crise do modelo que estabelece uma relação epistemológica hierárquica e unidirecional entre a investigação acadêmica e a prática profissional" (2008, p. 15). Apesar disso, as chamadas pesquisas colaborativas entre pesquisadores e docentes que propõem novos modelos para essas relações ainda carecem de mecanismos para levar à prática os resultados de um campo crescente de conhecimento e avaliar sua implementação nos espaços educativos.

Neste artigo, analisamos e contrastamos a prática pedagógica de dois professores de química envolvendo atividades experimentais e que ensinam em 
escolas pertencentes a diferentes contextos socioeconômicos. Essa análise nos possibilita uma breve discussão sobre como o uso dos resultados dessa pesquisa pode ser empregado na formação inicial e continuada de professores dessa disciplina acerca dos temas aqui tratados.

\section{SITUANDO O PROBLEMA}

Avaliação recente da aprendizagem em química por estudantes do segundo ano do ensino médio na Bahia, Brasil, revela um quadro desolador: considerado como muito crítico, encontra-se abaixo do resultado obtido para as disciplinas física e biologia (BAHIA, 2012). Inúmeros fatores podem estar configurando esse desempenho dos estudantes baianos, alguns deles velhos conhecidos dos debates sobre a educação química escolar: professores malformados, turmas superlotadas de alunos, currículo descolado dos contextos cotidianos, ausência de laboratórios escolares, ensino memorístico e atrelado à exploração da linguagem simbólica da química, tempo limitado para o ensino e aprendizagem, entre outros. Sem ignorar a contribuição de cada um desses elementos para o sombrio panorama, nossa pesquisa orienta-se por premissas que nos levam a olhar para o interior das salas de aula e os intercâmbios que nelas ocorrem. Acreditamos que, como espaços de comunicação, as salas de aula nem sempre constituem meios transparentes, e podem dar origem a incompreensões e desentendimentos entre aquilo que docentes e alunos tentam comunicar uns aos outros (SANTOS, 2013). Tais incompreensões e desentendimentos, quando acontecem, podem conduzir a rechaços e fracassos por parte dos estudantes.

A pesquisa em torno das interações discursivas interessa-se sobremaneira sobre os processos de cognição situada, ou seja, em como professores são capazes de contribuir com a promoção da aprendizagem de seus alunos em sala de aula, e considera a linguagem um artefato cultural mediador entre o conhecimento e os aprendizes (NASCIMENTO, 2007). Entretanto, a ênfase predominante dessa linha de pesquisa recai sobre o escrutínio das perguntas dos docentes aos estudantes, sobre as respostas destes ou sua participação no discurso do tipo argumentativo (LOUCA; ZACHARIA; TZIALLI, 2012). Investiga-se, principalmente, a relação entre esses intercâmbios e a aprendizagem dos conceitos e a aquisição da linguagem científica. No entanto, durante uma aula de química, diferentes tipos de episódios se integram sucessivamente, em sequências que correspondem não somente ao conteúdo a ser transmitido, mas também a estratégias de ensino que envolvem atividades e tarefas que os professores solicitam de seus alunos que as realizem. Para o êxito dessas estratégias, as interações verbais também constituirão um dos fatores determinantes do processo ensino-aprendizagem (ALTET, 2000). Sabemos, por outro lado, por meio de pesquisas etnográficas, que "o progresso nas lições escolares requer não apenas a compreensão estrita e passiva de conteúdo, mas a aquisição de competência de se envolver nas conversações em sala de 
aula” (SILVA; MORTIMER, 2010, p. 123). Cabe, então, também investigar esses intercâmbios ao redor da definição de atividades e tarefas e sua relação com o engajamento dos estudantes naquilo que lhes é proposto nas aulas de ciências.

Sobre a participação e o desempenho dos estudantes nas atividades e tarefas, alguns autores compreendem o engajamento daqueles como uma forma de trabalho configurado em uma dada organização:

Antes mesmo de se tornarem em momentos de aprendizagem, as actividades didácticas - escutar, intervir, responder a perguntas, resolver problemas, redigir - são tarefas consignadas aos alunos, que serão depois vigiadas, controladas e recompensadas pelo professor. (PERRENOUD, 1995, p. 117)

Sua participação e o trabalho solicitado exigem determinadas regras a serem conhecidas e obedecidas, e os estudantes, segundo Perrenoud, "tentam negociar ou virar a seu favor as regras e as ordens" (1995, p. 118). Segundo Doyle (citado por NUTHALL, 2000), a participação dos alunos é função das exigências impostas pelas tarefas, e seu engajamento, um produto da clareza das instruções, da ambiguidade de seus resultados e o grau de risco e de esforço que implicam completar a tarefa. O papel do professor como mediador que fornece os recursos adequados à execução da tarefa exige que este explicite aos seus alunos o que pretende destes, uma vez que estes com muita frequência têm uma noção muito vaga sobre o que devem fazer (LOPES et al. 2010).

A pesquisa sobre as interações discursivas em sala de aula nos informa sobre a existência de regras contextuais que são específicas das situações de comunicação que esses espaços sociais proporcionam. De acordo com Green (citado por CAZDEN, 1997), as atividades apresentam estruturas de participação cujas regras são implícitas e se transmitem e se aprendem por meio das interações. Tais regras e suas finalidades raras vezes se tornam explícitas e são definidas por Edwards e Mercer (1994) como regras educacionais básicas. Para esses autores, os problemas mais graves de comunicação na educação não se limitam às questões de conteúdo:

Los malentendidos más profundos y graves pueden ser los relacionados con las reglas subyacentes, implícitas, de interpretación, que definen como hay que 'tomar' y responder a trozos determinados de habla, texto o lenguaje en clase. (EDWARDS; MERCER, 1994, p. 76)

Considerando que cada disciplina escolar apresenta particularidades como esquemas gerais próprios, e que contribuem com o professor com exemplos, problemas, explicações e exercícios, aquelas regras educacionais básicas devem se constituir de maneira específica nas situações de ensino. Além disso, as atividades e tarefas adquirem grande importância para o ensino e a aprendizagem, em função de sua estreita relação com o aproveitamento e as avaliações dos estudantes. Interessa então averiguar como, por exemplo, em química, professores e alunos interagem discursivamente em torno da definição de tarefas e atividades, e como tais 
interações e intercâmbios contribuem para o êxito dos aprendizes na realização de seus trabalhos.

A pesquisa das interações discursivas em torno das atividades e tarefas vem assim completar aquela que investiga o ensino e a aprendizagem da linguagem e dos conceitos científicos, e procura conhecer como os professores são capazes de promover ou limitar o engajamento de seus estudantes nos ambientes de sala de aula e de tornar explícitas para estes as regras para sua participação, realização e avaliação de suas produções. Entretanto, ainda se encontra pendente para essa linha de investigação a integração dos contextos microssociais de interação, como a sala de aula, com os contextos sociais, culturais e históricos mais amplos que englobam aqueles. Segundo Daniels (1995), há uma persistente relutância dos adeptos das teorias originadas na psicologia, como a teoria sociocultural de Vigotsky, em considerar o mundo social para além das interações interpessoais que ocorrem em cenários particulares como as escolas. De fato, de acordo com Daniels, os efeitos dos processos de escolarização não são uniformes, pois as escolas diferem entre si e essas diferenças podem assumir significâncias sociais além daquelas psicológicas ou semióticas identificadas pelas pesquisas orientadas pela teoria sociocultural. E, se tais diferenças, por sua vez, implicam na desigualdade educativa, cabe também à pesquisa investigar como o discurso escolar é capaz de colaborar com a reprodução dessas desigualdades.

Para Gregory Kelly (2008), o discurso assume um papel central na mediação do conhecimento nas salas de aula e a aproximação dos pesquisadores das questões relacionadas com a equidade educativa de um ponto de vista da linguagem implica levar em conta que a aprendizagem é mediada não somente por fatores linguísticos, mas também por fatores sociais e culturais (LEE, 2005). Estudos que incluam os contextos educacionais como os cenários de nossas pesquisas exigem assim um marco teórico que dê conta das complexas relações entre linguagem, cultura e a sociedade mais ampla que abarca esses contextos, pois, entre as diferenças apontadas por Daniels como efeitos dos processos de escolarização, podem ser incluídas aquelas resultantes das maneiras como os professores de ciência promovem ou limitam o engajamento e a participação de seus estudantes nas atividades e tarefas realizadas em sala de aula e, desse modo, contribuem a aproximar ou afastar as crianças e os adolescentes da ciência.

\section{SOBRE A TEORIA DO DISCURSO PEDAGÓGICO}

Basil Bernstein, sociólogo da educação britânico, é um autor cuja obra está centrada nas relações entre linguagem e educação e, de acordo com ele, seria um papel da sociologia da educação "explicitar as formas como as instituições educacionais expressam características da sociedade da qual fazem parte" (SANTOS, 2003, p. 21). Em seu pensamento, a educação ocupa um papel central na produção e reprodução das desigualdades e injustiças sociais, e os vieses que 
a educação apresenta podem significar uma ameaça econômica e cultural para a democracia. Esses vieses, em sua compreensão, “están muy profundamente arraigados en la misma estructura de los procesos de transmisión y adquisición del sistema educativo y sus supuestos sociales" (BERNSTEIN, 1998, p. 24). Bernstein, por meio de sua teoria do discurso pedagógico, buscou tornar possível a descrição e a integração entre os níveis de interação, os institucionais e os macroinstitucionais em uma mesma formulação analítica e teórica. Como um sociólogo crítico do processo de escolarização, Bernstein inclui a pedagogia, o currículo e a avaliação como formas de controle social (MAINARDES; STREMEL, 2010).

Em Bernstein, o processo de comunicação pedagógica se constitui no mais importante meio de controle simbólico, por meio do qual as escolas são capazes de distribuir os estudantes quanto ao sucesso e fracasso escolar, internalizando hierarquias relacionadas com a estrutura social as quais são inscritas no próprio aparelho pedagógico (SANTOS, 2003). Por meio dos conceitos de classificação e enquadramento, que permitem a esse autor investigar as relações de poder e controle veiculadas pelos sistemas educacionais, seria possível caracterizar diferentes modalidades da prática pedagógica e como tais práticas proporcionam aos alunos os princípios necessários para elaborar os textos legítimos ${ }^{1}$. A classificação refere-se à delimitação de fronteiras entre sujeitos, discursos e objetos, enquanto o enquadramento refere-se à comunicação legítima para as diversas categorias de acordo com as fronteiras estabelecidas pelas relações de poder. Em outras palavras, a classificação compreende $o$ quê da prática pedagógica, enquanto o enquadramento, o como essa prática se realiza.

$\mathrm{O}$ autor reconhece dois conjuntos de regras presentes no enquadramento e que são chamadas de discurso regulativo e de discurso instrucional. O primeiro discurso refere-se à ordem social e o segundo, ao discurso sobre conhecimentos e habilidades. O discurso de instrução está sempre integrado ao discurso regulador, que constitui o discurso dominante (BERNSTEIN, 1998). Nos contextos educacionais, a classificação (ou o poder) permite aos sujeitos adquirir as regras de reconhecimento, pois por meio delas é possível reconhecer a especificidade de um determinado contexto. Já o enquadramento (ou o controle) permite aos sujeitos adquirir as regras de realização, as quais permitem, por sua vez, a produção do texto adequado àquele contexto em que se encontram (SANTOS, 2003). Esses dois conjuntos de regras constituem o código pedagógico (ROSA; VEIT, 2011). Segundo Bernstein, "el código es un principio regulador, adquirido de forma tácita, que selecciona e integra los significados relevantes, su forma de realización y los contextos evocadores" (1998, p. 138).

Diferentes modalidades de prática pedagógica apresentam valores distintos de classificação e enquadramento. Para Bernstein, esses valores variam entre forte e fraco. Uma classificação forte significa que as categorias estão bemseparadas entre si, e seus limites são bem-definidos, enquanto uma classificação fraca implica que os limites entre as categorias são menos definidos e o grau de separação entre elas é menor. Um enquadramento forte significa que o 
transmissor ${ }^{2}$ nas relações pedagógicas mantém um controle sobre a transmissão, enquanto, em uma modalidade com um enquadramento fraco, o transmissor apresenta um controle menor sobre a prática. A classificação traduz as relações de poder e estabelecem identidades e vozes, ao tempo em que constrói o espaço social com suas estratificações, distribuições e localizações. Aplicado a qualquer relação pedagógica, o conceito de enquadramento se refere ao controle sobre a comunicação e interações entre os sujeitos: ele inclui o controle sobre a seleção, a sequência, o ritmo ou compassamento e os critérios de avaliação (BERNSTEIN, 1998). Segundo Bernstein, os valores de enquadramento podem variar (entre forte e fraco) com respeito a qualquer um dos elementos da prática: “podemos tener un enmarcamiento débil en relación con el ritmo, pero fuerte con respecto a otros aspectos del discurso pedagógico" (p. 45).

De acordo com o modelo de discurso pedagógico de Bernstein, sem a regra de reconhecimento não é possível uma comunicação legítima em um determinado contexto. Como são as relações de poder que dão origem a diferentes distribuições sociais das regras de reconhecimento, ele acredita, por exemplo, que "en un nivel más concreto, es muy posible que algunos niños de las clases sociales desfavorecidas se mantengan en silencio en la escuela a causa de la distribución desigual de las reglas de reconocimiento" (BERNSTEIN, 1998, p. 49). Entretanto, possuir a regra de reconhecimento não garante que os sujeitos serão capazes de produzir uma comunicação legítima. Nesse caso eles não possuem a regra de realização e, desse modo, são incapazes de produzir o texto legítimo esperado. A aquisição das regras de realização, por sua parte, depende dos valores de enquadramento da prática pedagógica.

A aplicação da teoria do discurso pedagógico de Basil Bernstein ao estudo dos processos de escolarização na área de ciências tem sido realizada pelo grupo português ESSA (Estudos Sociológicos da Sala de Aula), liderado pela pesquisadora Ana Maria Morais. Ampliando o escopo da teoria de Bernstein com o socioconstrutivismo de Vigotsky, muitos de seus estudos e pesquisas buscaram verificar quais as características da prática pedagógica mais favorável para a aquisição de conhecimento e de competências científicas por estudantes de diferentes origens sociais. Entre suas descobertas que são de especial interesse para nós, encontra-se aquela que mostra que o efeito da prática pedagógica pode se sobrepor ao efeito da origem social dos estudantes e sugerem um modelo de pedagogia mista para uma aprendizagem científica, social e afetiva bem-sucedida (MORAIS; NEVES, 2001). Nessa modalidade de prática pedagógica, os elementos que caracterizam as relações de enquadramento são alterados de modo a tornar explícitos para os estudantes os critérios de avaliação, um enfraquecimento da ritmagem e do sequenciamento, e também uma alteração na classificação do espaço da sala de aula, enfraquecendo o espaço entre professores e alunos (HOADLEY; MULLER, 2013).

Neste artigo, para a análise das interações discursivas de dois professores de química durante a definição de atividades experimentais, buscaremos caracterizar as práticas pedagógicas de acordo com as chamadas regras discursivas que 
constituem o enquadramento: a seleção, a sequência, a ritmagem, os critérios de avaliação e a relação entre discursos acadêmico e não acadêmico. Com essa análise, verificaremos se é possível identificar os elementos presentes da prática que facilitam ou dificultam, para os estudantes, a aquisição das regras de realização com respeito às atividades e tarefas definidas pelos professores por meio das quais é possível produzir o texto legítimo e adequado ao contexto das aulas de química.

\section{OS CENÁRIOS E OS SUJEITOS DA PESQUISA}

Os dados empíricos apresentados e analisados neste artigo foram coletados em duas escolas da cidade de Jequié ${ }^{3}$, Estado da Bahia, Brasil. Uma delas é uma escola privada localizada na zona central da cidade, que atende principalmente estudantes oriundos de famílias da classe média local. A grande maioria dos estudantes, ao término do ensino médio, procura ingressar em alguma instituição de ensino superior. A outra escola é pública, pertencente à rede estadual da Bahia, e está situada em um bairro periférico. Seus estudantes, cuja maioria pertence às classes populares, ao fim do ensino médio procuram inserir-se no mercado de trabalho local, que tem como principais atividades econômicas o comércio e a indústria de transformação.

Os dois professores de química que participaram dessa pesquisa possuem trajetórias profissionais levemente distintas: a professora da escola pública é formada em ciências com concentração em química, possui especialização em ensino de ciências e mais de dez anos de experiência profissional como docente. O professor da escola privada é professor de química e mestre em química analítica, atuando em sala de aula há cinco anos. As turmas que foram observadas correspondem ao primeiro ano do ensino médio. Na escola privada a turma observada possuía 38 alunos, enquanto na escola pública, um total de 36.

\section{Procedimentos metodológicos}

Os dados apresentados neste artigo somente foram coletados após a aprovação pelo Comitê de Ética de nossa Universidade do projeto de pesquisa que dá origem a este trabalho. Os sujeitos pesquisados estavam cientes de nossa investigação por meio dos termos de consentimento livre e esclarecido e de autorização do uso de imagens e depoimentos. Ambas as turmas foram acompanhadas pelos pesquisadores durante duas unidades letivas, que abrangem aproximadamente quatro meses de aulas. Nossas observações eram registradas em caderno de campo, e as aulas foram gravadas em áudio e posteriormente transcritas. Dois gravadores digitais foram utilizados na gravação das aulas, um próximo à mesa do professor e outro próximo aos alunos. Após a transcrição procurouse identificar os marcadores de fronteiras que indicam os diferentes momentos das aulas, pois por meio de sua localização foi possível fragmentar cada classe em seus episódios. Com isso, cada aula foi reconstruída como um mapa de episódios, o que 
permitiu a identificação e a classificação de cada tipo de atividade desenvolvida nas aulas e seu respectivo tempo ${ }^{4}$.

Os dados apresentados e analisados correspondem a fragmentos de aulas em que os professores definiam e organizavam atividades experimentais. A opção por essa escolha deve-se a que, em primeiro lugar, ambos os professores desenvolveram esse tipo de atividade durante o período em que suas aulas foram observadas, embora seus métodos de trabalho fossem bastante distintos entre si com relação ao modo em que tais atividades eram desenvolvidas. A professora costuma desenvolver aulas experimentais como demonstrações para seus alunos, enquanto o professor solicita que seus estudantes realizem pequenos experimentos fora da escola e registrem e apresentem seus resultados como tarefa de casa. Em um trabalho prévio sobre o estado da arte da pesquisa sobre linguagem e discurso no ensino de ciências no Brasil, encontramos que o laboratório - e as atividades experimentais, em consequência - tem sido um espaço muito pouco explorado nesse tipo de pesquisa (SOUZA et al., 2013). Devido à importância que a experimentação assume para a educação científica, consideramos que seria frutífero o contraste entre as duas metodologias empregadas pelos docentes investigados.

Para a caracterização das práticas pedagógicas foram utilizados instrumentos de análise baseados e adaptados dos trabalhos do grupo ESSA e outros construídos e propostos por nós, com base nos registros das observações e em nossas questões de pesquisa. Esses instrumentos de análise constituem indicadores das regras discursivas, e cada indicador apresenta uma escala de valores com quatro graus de classificação e enquadramento, a qual varia entre muito forte a muito fraco $\left(\mathrm{C}^{++}, \mathrm{C}^{+}, \mathrm{C}^{-}, \mathrm{C}^{--} ; \mathrm{E}^{++}, \mathrm{E}^{+}, \mathrm{E}^{-}, \mathrm{E}^{--}\right)$. Com base nos resultados obtidos, foi possível caracterizar a prática pedagógica de cada um dos professores e comparar as características dessas práticas entre si.

\section{ANÁLISE DOS DADOS}

O quadro 1 abaixo apresenta um indicador utilizado na caracterização do contexto instrucional da prática pedagógica, referente à regra discursiva critério de avaliação, seguido de exemplos de fragmentos de nossa transcrição, que mostram valores diferenciados para o enquadramento dessa regra nas duas situações descritas nos exemplos, baseados na escala apresentada acima. A professora da escola pública é representada como PB e o professor da escola privada como PC. 
Quadro 1: Exemplo de um indicador de análise da regra discursiva critério de avaliação e exemplos de fragmentos.

\begin{tabular}{|c|c|}
\hline \multicolumn{2}{|r|}{ Indicador: Definição da tarefa quanto à sua organização } \\
\hline $\mathrm{E}^{++}$ & $\begin{array}{l}\text { O professor propõe uma tarefa e explicita de forma pormenorizada as } \\
\text { informações para a realização e organização da tarefa. }\end{array}$ \\
\hline $\mathrm{E}^{+}$ & $\begin{array}{l}0 \text { professor propõe uma tarefa e fornece algumas informações para a } \\
\text { realização e organização da tarefa. }\end{array}$ \\
\hline $\mathrm{E}^{-}$ & $\begin{array}{l}\text { O professor propõe uma tarefa fornecendo informações para a sua realização, } \\
\text { mas não fornece informações quanto à organização da tarefa. }\end{array}$ \\
\hline $\mathrm{E}^{-}$ & $\begin{array}{l}\text { O professor propõe a tarefa e não fornece nenhuma informação quanto a } \\
\text { realização nem quanto à organização da tarefa. }\end{array}$ \\
\hline
\end{tabular}

PB (E'): (Após a realização de uma atividade experimental na sala de aula, sob a forma de uma demonstração, a professora comunica aos alunos o que ela quer para a próxima aulal

Prof.: Silêncio! Pessoal, atenção! Eu quero que vocês anotem para de hoje a oito... Eu quero que vocês pesquisem tudo que eu pedi aqui hoje e tragam para a sala de aula por que aqui vocês irão produzir um texto de hoje a oito. Nós iremos produzir um texto aqui na sala com esses resultados então todo mundo pesquisa porque de hoje a oito nós iremos relatar tudo que aconteceu na forma de texto para me entregar de hoje a oito...

PC $\left(\mathrm{E}^{++}\right)$: 10 professor vem descrevendo para seus alunos o procedimento experimental que eles deverão realizar em casa e, após a descrição, ele define o que seus alunos devem apresentar para ele na próxima aulal

Aluno: Pode fazer um vídeo?

Prof.: Pode fazer um vídeo, tudo bem! Mas além desse vídeo o que eu quero é a foto. Que isso fique muito claro, tá? Que vocês tirem fotografia de todo o sistema. Primeiro você vai juntar todos os materiais todos os reagentes, presta atenção viu! Para depois não falar que eu não expliquei direito, que no dia tem que está do jeito que eu estou explicando. Vocês vão para cada prática para cada sistema tirar uma fotografia e perceber se a lâmpada acendeu ou não. Após feito isso você pode juntar todos os reagentes e o sistema de vocês e tirar uma foto única o reagente e o material. Eu quero isso no caderno. Vocês podem imprimir ou revelar a foto... mas eu quero que a foto esteja no caderno. A foto tem que constar no caderno. 0 procedimento eu quero no caderno.

A regra discursiva critério de avaliação diz respeito ao controle que o transmissor apresenta sobre os procedimentos de correção das diversas produções que os alunos realizam, seja uma síntese de um conteúdo, as respostas às perguntas dos professores, os trabalhos de casa ou as avaliações tipo exames. Nesse indicador selecionado, quanto mais pormenorizada for a instrução do professor com respeito à realização da tarefa, mais forte será o enquadramento apresentado por essa regra. Nas situações registradas, a professora PB indica que os alunos deverão produzir um texto com os resultados obtidos da atividade experimental, mas não fornece detalhes sobre a produção desse texto, enquanto o professor PC detalha bastante a apresentação dos resultados da tarefa, indicando como os alunos devem produzir seu trabalho.

Outro indicador definido por nós relaciona-se com a ritmagem. Uma etapa prévia ao desenvolvimento das atividades experimentais era a distribuição dos roteiros dos procedimentos entre os alunos, seguida da leitura em sala de aula. Episódios como esses foram observados nas duas práticas pedagógicas e deram origem ao indicador Leitura do procedimento experimental, cujos valores de enquadra mento e exemplos de fragmentos são apresentados no Quadro 2. 
Quadro 2: Indicador de análise da regra discursiva ritmagem e exemplos de fragmentos.

\begin{tabular}{|c|r|}
\hline \multicolumn{2}{|c|}{ Indicador: Leitura do procedimento experimental } \\
\hline $\mathrm{E}^{++}$ & $\begin{array}{r}\text { O professor distribui o roteiro do procedimento experimental e solicita que } \\
\text { os alunos leiam o roteiro, mas não fornece tempo suficiente para a leitura, } \\
\text { interrompendo-a antes. }\end{array}$ \\
\hline $\mathrm{E}^{+}$ & $\begin{array}{r}\text { O professor distribui o roteiro do procedimento experimental e realiza a leitura } \\
\text { na íntegra com seus alunos, sem pausa para questionamentos. }\end{array}$ \\
\hline $\mathrm{E}^{-}$ & $\begin{array}{r}\text { O professor distribui o roteiro do procedimento experimental e realiza a } \\
\text { leitura na íntegra do mesmo para os alunos, permitindo questionamentos e } \\
\text { comentários dos alunos durante a leitura. }\end{array}$ \\
\hline $\mathrm{E}^{--}$ & $\begin{array}{r}\text { O professor distribui o roteiro do procedimento experimental e permite } \\
\text { que os alunos leiam o roteiro, fornecendo tempo suficiente para a leitura e } \\
\text { questionamentos por parte dos alunos. }\end{array}$ \\
\hline
\end{tabular}

PB $\left(E^{+}\right)$: (A professora solicita a uma aluna que distribua entre seus colegas cópias do roteiro do procedimento experimental; ela não providenciou cópias suficientes para todos)

Prof.: Vou dar um tempo para que vocês façam a leitura do roteiro de aula experimental de hoje a leitura deve ser feita em dupla, porém, todos devem fazer suas anotações de forma individual, todos têm que ter atenção e não é permitido conversas paralelas então quem gosta de conversar pode tratar de esquecer... (lquatro minutos após anunciar que iria dar um tempo para que os alunos realizassem a leitura do procedimento, a professora retoma a palavral)

Prof.: Vamos começar a nossa aula experimental de hoje. Então o tema de hoje é/são ligações químicas. Inicialmente gostaria de solicitar de alguém para fazer a leitura, quem começa a leitura?

PC (E) : 10 professor anuncia que ele vai ler com os alunos o roteiro de uma atividade experimental que eles irão realizar em casa, sobre criação e testes de indicadores ácido-base)

Prof.: Vamos lá? Prestem atenção na leitura da prática...tirem dúvidas após eu ler, tá? Não interrompam a leitura, tirem dúvidas após eu ler, prestem atenção para não fazerem errado,


prático e a turma fica em silênciol) “Prática de ciências 2 - Preparando indicador ácido-base... Os indicadores orgânicos geralmente são moléculas orgânicas muito complexas e suas cores dependem do meio em que estes encontram-se dissolvidos. Muitos desses indicadores são obtidos a partir de espécies vegetais como pétalas, tubérculos, flores, frutas, etc. Você pode preparar uma série de indicadores e testar suas variações de cor em meio: ácido, básico e neutro... Objetivo... Neste experimento você vai estudar por meio de indicadores ácido-base alternativos a natureza ácida ou básica de uma série de materiais domésticos... Material: 21 copos transparentes (vidro ou descartáveis), beterraba, pétalas de rosa vermelha", pétalas de rosa vermelha... se vocês chegarem em uma floricultura eles fornecem tranquilamente uma quantidade e não precisa comprar, ta? Por que eles sempre têm aquelas pétalas murchas.

Então vocês não precisam comprar. "Repolho roxo, álcool hidratado", o álcool doméstico... Líquido e não em gel... um pouco de álcool líquido... "Três folhas de papel filtro", aquele papel utilizado como coador, por que você tem o papel filtro e tem o coador que é aquele recipiente de plástico, ta? Então três folhas (luma aluna interrompe a leitura para fazer uma pergunta))

Aluna1: onde é que eu acho isso?

\section{Prof.: SUPERMERCADO}

Aluna 2: E eu posso usar aquele de pano?

Prof.: Pode ser o de pano... eu pus o de papel por que eu acreditava que a maioria tinha o de papel Alunos: compra aquela caixa? 


\begin{tabular}{|c|c|}
\hline \multicolumn{2}{|c|}{ Indicador: Registro dos dados e informações da atividade experimental } \\
\hline $\mathrm{E}^{++}$ & $\begin{array}{r}\text { O professor discute os prováveis resultados a serem observados no } \\
\text { experimento e o modo adequado de registrá-los. }\end{array}$ \\
\hline $\mathrm{E}^{+}$ & $\begin{array}{r}\text { O professor discute os prováveis resultados, mas deixa a cargo dos alunos } \\
\text { a decisão sobre o modo de registrá-los, indicando somente que eles devem } \\
\text { anotar suas observações e os resultados. }\end{array}$ \\
\hline $\mathrm{E}^{-}$ & $\begin{array}{r}\text { 0 professor discute os prováveis resultados, mas não comenta sobre as } \\
\text { anotações das observações e resultados, embora solicite uma produção escrita } \\
\text { sobre o experimento. }\end{array}$ \\
\hline $\mathrm{E}^{--}$ & $\begin{array}{r}\text { O professor não discute os prováveis resultados nem as observações e } \\
\text { anotações que os alunos devem proceder, mas solicita deles uma produção } \\
\text { escrita sobre o experimento. }\end{array}$ \\
\hline \multicolumn{2}{|c|}{ Indicador: Registro dos dados e informações da atividade experimental } \\
\hline
\end{tabular}

PB (E'): (Após realizar o procedimento experimental em aula, a professora lê e discute com seus alunos a produção escrita que eles deverão apresentar na próxima aula, a partir dos resultados observados)

Prof.: Construa uma tabela separando as substâncias em: iônicas, metálicas e covalentes. Lembram do último procedimento que diz assim: construa uma tabela com os resultados observados, agora essa tabela vai ser a mesma agora, como será essa tabela? Vocês vão construir uma tabela colocando na primeira coluna as substâncias... todas as substâncias que nós analisamos o nome das substâncias, ok? Na segunda coluna, vocês vão colocar a fórmula das substâncias, por exemplo, a sacarose mesmo vocês não têm a fórmula da sacarose vocês vão ter que pesquisar essa fórmula química. Novamente, na primeira coluna da tabela, vocês

vão colocar o nome substâncias, por exemplo, o nome da substância cloreto de potássio, cobalto hexa hidratado na outra coluna vocês vão colocar a fórmula. Em uma coluna vocês vão colocar o nome, na outra coluna vocês vão colocar a fórmula, todo mundo entendeu? Numa coluna o nome, na outra coluna a fórmula, na outra coluna vocês vão analisar, certo? Vocês vão analisar vocês podem colocar o nome assim, iônica, metálica e covalente aí vocês vão dizer: qual dessas substâncias qual é iônica? qual é covalente? e qual é metálica?

PC $\left(\mathrm{E}^{++}\right)$: 10 professor depois de ler o roteiro e responder a diversas perguntas dos alunos, começa a informá-los como apresentar seus resultados experimentais a fim de cumprir com os objetivos do experimentol

Prof.: Então, após realizar a prática é que você preenche essa tabela e vai para a tabela lá de cima especificar o caráter, estão vendo? llo professor indica com o dedo as tabelas das quais está a falar)\}. Então você vai preencher essa tabela aqui, aí depois você volta para a tabela de cima do caráter... bom e o limão? Tem caráter ácido? É meio básico ou neutro? E assim para todas as substâncias. Após você perceber que em meio ácido tal indicador fica tal cor... em meio básico tal cor...em meio neutro fica tal cor.

Aluna: a gente vai se basear pela cor que vai ficar ou a gente tipo assim...o limão é ácido, mas a minha coloração indicou que ele não era ácido, mas como eu sei, eu coloco aqui ou não?

Nos exemplos apresentados no Quadro 3, os professores PB e PC se diferenciam com respeito às instruções fornecidas para os registros dos dados experimentais: o roteiro distribuído por PC traz as tabelas já construídas que os alunos preencherão, enquanto na prática de $\mathrm{PB}$ os próprios alunos constroem a tabela para o registro dos dados.

Outro indicador associado às atividades experimentais e que pode ser 
identificado nas práticas pedagógicas dos dois professores diz respeito à relação entre os discursos acadêmico e não acadêmico. Esses discursos, no caso das atividades experimentais, assumem as características do fato científico e da evidência empírica associados ao experimento, conforme discutido por Antonia Candela (1999). Relacionando-o com o nosso problema de pesquisa, esse indicador nos informa como os professores orientam discursivamente seus alunos quanto à observação a ser realizada e qual a primazia assumida pelo fato científico associado com o fenômeno sob observação. Os valores que atribuímos a ele se relacionam com o grau de importância do fato científico frente à evidência empírica e são observados no Quadro 4.

Quadro 4: Indicador de análise da regra discursiva relação entre discursos acadêmico e não acadêmico.

\begin{tabular}{|c|c|}
\hline \multicolumn{2}{|r|}{ Indicador: Relação entre o fato científico e a evidência empírica } \\
\hline $\mathrm{E}^{++}$ & $\begin{array}{c}\text { O professor dá primazia ao conhecimento do fato científico em relação à } \\
\text { evidência empírica. }\end{array}$ \\
\hline $\mathrm{E}^{+}$ & $\begin{array}{l}\text { O professor dá primazia ao conhecimento do fato científico, mas pontualmente } \\
\text { destaca a evidência empírica. }\end{array}$ \\
\hline$E^{-}$ & $\begin{array}{l}\text { O professor dá primazia ao conhecimento do fato científico, mas destaca com } \\
\text { frequência a evidência empírica. }\end{array}$ \\
\hline$E^{--}$ & $\begin{array}{c}\text { O professor dá primazia ao conhecimento do fato científico, mas sempre } \\
\text { enfatiza pra seus alunos a evidência empírica. }\end{array}$ \\
\hline
\end{tabular}

PB $\left(\mathrm{E}^{++}\right)$: (Antes de realizar a atividade experimental, a professora solicita que uma aluna leia $o$ procedimento que vai sendo comentado por elal

Aluna: "solução eletrolítica ou solução iônica é aquela que (inaudível) e, portanto, é condutora elétrica. Solução molecular ou não eletrolítica é aquela que não contém íons"

Prof.: um minutinho por favor... olha só aqui já temos duas informações EXTREMAMENTE importantes. A primeira é que a solução eletrolítica ou iônica, ela vai ser condutora de corrente elétrica, então o que isso significa? que quando nós tivermos aqui e introduzir os eletrodos em alguns materiais a lâmpada acende se a lâmpada acende significa que a substância é condutora de eletricidade continue...

PC ( $\mathrm{E}^{-}$): (A leitura do procedimento é comentada e discutida pelo professor ao tempo em que ele vai respondendo às dúvidas dos alunos)

Prof.: Então você vai ter nesses três recipientes um para cada indicador então eu vou querer para cada material uma foto tente tirar uma foto de cima para baixo que o interessante é que a gente consiga visualizar o quê? A mudança de?... coloração. Uma coisa bacana que muitos fizeram é pôr legenda, eu acho que isso facilita.

A primazia do conhecimento do fato científico dada pela professora $\mathrm{PB}$ pode ser apreciada em outro fragmento, onde uma pergunta emitida pela professora cuja resposta envolvia o conhecimento da evidência empírica termina sendo respondida pela aluna, erroneamente, com o conhecimento do fato científico, mostrado no Quadro 5:

Quadro 5: Quadro com fragmento de aula da professora PB representando 0 indicador relação entre a evidência empírica e o fato científico. 
PB $\left(\mathrm{E}^{++}\right)$: (A professora realiza o teste de chama com diferentes sais de metais para que seus alunos observem a cor produzidal

Prof.: 0 que vocês estão observando que aconteceu aqui? Quem pode falar sobre o que observou?...Quando colocou fogo aqui... Quando colocou fogo aqui, o que a gente observou de diferente?... O que é que aconteceu de diferente?

Aluna: Aconteceu uma reação química

Prof.: Aconteceu uma reação química sim, mas o que é que foi que aconteceu de diferente?

Aluna: As cores?

Prof.: As cores vocês sabem, mas ficam com medo de falar...cada um desse sal emitiu o quê? Uma... uma...co-lo-ra-ção diferente, mas o que foi que proporcionou essa coloração diferente?...Vocês estão lembrados lá do modelo atômico de Bohr?

A resposta desejada pela professora só foi posteriormente respondida, ainda que timidamente (em tom de pergunta “as cores?”) pela aluna. A resposta inicial da aluna ilustra a primazia do conhecimento do fato científico sobre a evidência empírica, pois os alunos não compreendem que as perguntas da professora PB endereçadas à observação do experimento admitam respostas envolvendo um conhecimento do âmbito não acadêmico ou do senso comum.

Por último, um indicador identificado em nossas observações relaciona-se com a regra discursiva seleção e diz respeito às interpretações e conclusões das observações. Entendemos, nesse caso, que as interpretações e conclusões do trabalho experimental estão diretamente vinculadas com a realização da atividade pelo aluno e seus resultados. Seus valores são apresentados abaixo no Quadro 6:

Quadro 6: Indicador de análise da regra discursiva seleção.

\begin{tabular}{|c|c|}
\hline \multicolumn{2}{|c|}{ Indicador: Nas observações, interpretações e conclusões do trabalho experimental } \\
\hline $\mathrm{E}^{++}$ & 0 professor indica o que deve ser observado e interpretado e tira as conclusões. \\
\hline $\mathrm{E}^{+}$ & $\begin{array}{l}\text { O professor indica o que deve ser observado e interpretado e tira as conclusões, } \\
\text { mas aceita, pontualmente, sugestões dos alunos. }\end{array}$ \\
\hline$E^{-}$ & $\begin{array}{l}\text { O que deve ser observado, interpretado e concluído é definido pelo professor } \\
\text { em conjunto com os seus alunos. }\end{array}$ \\
\hline $\mathrm{E}^{--}$ & $\begin{array}{l}\text { Os alunos selecionam o que deve ser observado, interpretado e discutem as } \\
\text { conclusões com a ajuda do professor. }\end{array}$ \\
\hline
\end{tabular}


PB $\left(\mathrm{E}^{++}\right)$: (A professora realiza o teste de chama com diferentes sais de metais para que seus alunos observem a cor produzidal

Prof.: Vamos trabalhar com este aqui, porque eu acredito que foi o que emitiu uma cor que vocês mais perceberam, não foi? Então nós aqui colocamos o sulfato de cobre adicionamos um pouco de álcool e acendemos o fósforo, ocorreu uma reação, ocorreu uma reação por causa do oxigênio... do oxigênio presente no ar. 0 que foi que aconteceu com este elemento químico cobre aqui? Esse elemento químico cobre, ele foi excitado então ele saiu da camada de valência, vamos imaginar que tenha sido essa daqui... (IPB escreve no quadro um modelo para 0 átomo de cobre)l.

PC (E-): 10 professor discute com seus alunos como preencher a tabela que ele solicita seja preenchida com os resultados experimentais da atividade. Ele insiste que os resultados devem ser estritamente aqueles obtidos experimentalmente pelos alunos de modo individual)

Prof.: Após realizar todos os testes preencha a tabela abaixo de acordo com seus resultados obtidos. Eu quero os seus resultados se o seu resultado não deu semelhante ao de alguém repita a prática. Se o seu persiste então coloque o seu resultado, foi o que você obteve de resultado, não é para pegar o resultado do colega ou pesquisar na internet e colocar cores que você não conseguiu encontrar até porque eu vou querer fotografia então, eu quero o seu resultado é o que vocês obtiveram na prática...

O professor PC, ainda que oriente os alunos sobre o que observar no experimento, ao insistir com seus alunos que os resultados registrados devem ser estritamente aqueles observados e não os previstos, não antecipa as interpretações e conclusões do mesmo modo observado com a professora PB. Isso pode ser verificado no fragmento abaixo, conforme o Quadro 7, em que uma aluna questiona se seu resultado diferir daquele esperado por ela, como ela deve produzir a atividade.

Quadro 7: Quadro com fragmento de aula do professor PC representando o indicador observações, interpretações e conclusões do trabalho experimental.

PC : 10 professor está detalhando a atividade experimental já lida no procedimento e tirando dúvidas dos alunos)

Aluna: A gente vai se basear pela cor que vai ficar ou a gente tipo assim...o limão é ácido, mas a minha coloração indicou que ele não era ácido, mas como eu sei, eu coloco aqui, ou não?

Prof.: Não, o seu resultado. E muito dificilmente a coloração não vai ficar porque o papel dela é indicar para você.

Os resultados encontrados nessas duas práticas pedagógicas podem ser organizados de modo a permitir uma "visualização" de cada modalidade de prática desenvolvida por PB e por PC, conforme dispostos na Tabela 1:

Tabela 1: Caracterização das práticas pedagógicas dos professores PB e PC.

\begin{tabular}{|c|c|c|}
\hline Indicador & Professora PB & Professor PC \\
\hline $\begin{array}{c}\text { Definição da tarefa quanto à } \\
\text { sua organização }\end{array}$ & $\mathrm{E}^{-}$ & $\mathrm{E}^{++}$ \\
\hline
\end{tabular}

Revista Ensaio | Be10 Horizonte | v.16 | n. 03 | p. 227-246 | set-dez | 2014 


\begin{tabular}{|c|c|c|}
\hline $\begin{array}{c}\text { Leitura do procedimento } \\
\text { experimental }\end{array}$ & $\mathrm{E}^{+}$ & $\mathrm{E}^{-}$ \\
\hline $\begin{array}{c}\text { Registro dos dadose } \\
\text { informações da atividade } \\
\text { experimental }\end{array}$ & $\mathrm{E}^{-}$ & $\mathrm{E}^{++}$ \\
\hline $\begin{array}{c}\text { Relação entre a evidência } \\
\text { empírica e o fato científico }\end{array}$ & $\mathrm{E}^{++}$ & $\mathrm{E}^{-}$ \\
\hline $\begin{array}{c}\text { Nas observações, } \\
\text { interpretações e conclusões } \\
\text { do trabalho experimental. }\end{array}$ & $\mathrm{E}^{++}$ & \\
\hline
\end{tabular}

Podemos observar, nos valores atribuídos a cada indicador, que a professora PB apresenta uma tendência a um enquadramento mais forte em sua prática pedagógica com respeito às instruções sobre as tarefas relacionadas com as atividades experimentais que o professor PC. Isso significa que a professora PB tende a exercer maior controle sobre a comunicação com seus alunos que PC, que permite uma maior participação e condução de seus alunos nas interações discursivas ao redor das instruções sobre a tarefa. Uma olhada mais atenta aos resultados encontrados nos revela, entretanto, que PC apresenta um enquadramento muito forte exatamente naqueles indicadores mais diretamente relacionados à instrução sobre produção da atividade pelos alunos, enquanto PB, ao contrário, apresenta um enquadramento fraco nesses mesmos indicadores. Daí se pode concluir que os alunos de PC estariam recebendo instruções mais precisas e detalhadas que os alunos de PB sobre a forma que devem conduzir e preparar suas atividades. Os indicadores que a prática de PC apresenta enquadramento fraco ou muito fraco são aqueles relacionados às intervenções dos alunos nos momentos de definição das tarefas; isso significa que os alunos de PC contam com maior liberdade para interferir nas definições e na organização das atividades, enquanto o forte enquadramento apresentado por PB, por sua vez, representa uma prática em que os alunos têm pouca margem de manobra para decidir, em conjunto com a professora, sobre as atividades experimentais e as definições ao redor dos trabalhos que serão produzidos por eles a partir de suas instruções.

Ao levar em conta as características dos contextos socioeconômicos onde tais práticas pedagógicas se desenvolvem, podemos considerar que os alunos de PB interagem e participam menos que os alunos de PC, ou seja, aqueles alunos de uma origem social mais vulnerável têm menos oportunidade de participar das definições ao redor da química, uma vez que suas possíveis contribuições são menos estimuladas e permitidas que os alunos de uma origem social mais estabilizada. Isso é particularmente evidente quando se observa os valores de enquadramento dos dois últimos indicadores da Tabela 1, pois as observações, interpretações e conclusões dos alunos de PB são menos consideradas que as dos alunos de PC. As relações estabelecidas entre o conhecimento acadêmico e não acadêmico ao redor da definição da evidência empírica a ser observada não são temas menores nas aulas de química, pois, segundo Lemke, "la forma en que planteamos la relación 
entre el conocimiento académico y el sentido común, entre hablar científicamente y hablar de otras maneras sobre un tema, conlleva ciertos valores y prejuicios" (1997, p. 60). Esse mesmo autor nos indica que, com muita frequência, o ensino de ciências tem maior êxito em convencer os alunos de que uma disciplina científica é "inherentemente mucho más compleja y difícil que las otras materias, de tal manera que los alumnos nunca la entenderán realmente" (p. 141).

Por último, um dado importante diz respeito ao currículo de química e sua relação com a seleção e a ritmagem. O professor PC conta com quatro aulas por semana para desenvolver seu programa, enquanto que as escolas públicas disponibilizam para PB apenas duas aulas. É muito provável que o enquadramento forte observado na prática pedagógica de PB seja, em parte, o resultado da busca por desenvolver um currículo com os mesmos conteúdos que PC desenvolve pois é o currículo científica e socialmente reconhecido como o conjunto de conhecimentos da química a que os estudantes devem ter acesso - em um tempo menor. Percebemos tal esforço como algo positivo, pois demonstra que PB oportuniza a seus alunos um currículo muito próximo ao dos alunos de PC. Entretanto, tal enquadramento pode estar significando menos oportunidade para a aprendizagem da química por seus estudantes ou mesmo o seu rechaço a essa disciplina.

Por fim, gostaríamos de destacar que os resultados da análise efetuada neste artigo representam estratégias diferentes de ensinar química e que se relacionam com as concepções individuais de cada docente. Suas práticas pedagógicas, entretanto, não são resultado exclusivo de suas idiossincrasias, mas das interações que acontecem nos diferentes contextos onde eles ensinam.

\section{CONSIDERACְ̃̃ES FINAIS}

O uso da teoria do discurso pedagógico de Basil Bernstein e de seu desenvolvimento como elaborado pelo grupo ESSA para a investigação das interações discursivas em aulas de química nos resultou de grande potencial para a caracterização da prática pedagógica, e para o contraste dessas práticas entre si, considerando os cenários socioculturais distintos de nossa pesquisa. Por meio das análises desenvolvidas, foi possível verificar as diferentes estratégias empregadas pelos professores de química ao redor da instrução sobre as atividades experimentais e ponderar sobre quais situações se mostraram mais favoráveis para a consecução das tarefas pelos alunos. A análise realizada, no entanto, deve levar em conta aspectos como a carga horária disponibilizada a cada professor em suas respectivas escolas, pois, sob condições menos favoráveis, a professora da escola pública empreende uma prática pedagógica ilustrada por procedimentos experimentais em sala de aula que, na prática do professor da escola privada, são conduzidos como tarefas de casa.

A investigação da linguagem e das interações discursivas no ensino de ciências deve permitir, segundo Gregory Kelly, examinar "o que conta como ciência em um dado contexto, como a ciência é produzida nas interações, quem par- 
ticipa da construção da ciência e como as definições situadas da ciência implicam em orientações epistemológicas" (2008, p. 443). Entendemos que nossa pesquisa é capaz de contribuir para a compreensão de como professores oportunizam a seus alunos os espaços e tempos para sua participação ao redor da construção do conhecimento científico em sala de aula, especialmente em torno do desenvolvimento de atividades experimentais nas aulas de química, tão fundamentais para a aprendizagem dessa ciência.

Por fim, acreditamos que o conhecimento gerado aqui tem potencial para ser trabalhado na formação de professores - inicial e contínua, com possibilidades de que os professores, ao acederem os resultados da investigação, possam refletir sobre suas próprias práticas e questionar o lugar ocupado pela instrução das atividades e tarefas que logram desenvolver e sua relação com o desempenho e o engajamento de seus alunos.

\section{NOTAS}

${ }^{1}$ Para Bernstein, um texto legítimo significa qualquer atividade ou tarefa realizada pelo estudante que merece ser avaliada.

${ }^{2}$ Bernstein utiliza os termos transmissores e adquirentes para referir-se aos sujeitos das relações pedagógicas, mas tais termos não carregam juízos de valor com respeito à modalidade da prática. Ver comentário de Rosa e Veit (2011, p. 298) a esse respeito.

${ }^{3}$ Essa cidade possui em torno de 160 mil habitantes e se encontra a $360 \mathrm{~km}$ da capital do Estado, Salvador.

${ }^{4}$ Uma breve discussão sobre os procedimentos metodológicos para a análise de dados oriundos de interações em sala de aula pode ser encontrada em Mortimer et al. (2007).

\section{REFERÊNCIAS}

ALTET, M. Análise das práticas dos professores e das situações pedagógicas. Porto: Porto Editora, 2000. BAHIA. Avalie Ensino Médio 2012. Revista do Sistema de Avaliação. Juiz de Fora, v. 3, 2012.

BERNSTEIN, B. Pedagogía, control simbólico e identidad. Madrid: Morata, 1998.

CANDELA, A. Ciencia en el aula: los alumnos entre la argumentación y el consenso. México, DF: Paidós, 1999.

CAZDEN, C.B. El discurso del aula. In: WITTROCK, M. (comp.). La investigación de la enseñanz̧a, Barcelona, v. 3, 1997. p. 627-709.

COLL, C.; EDWARDS, D. (org.). Ensino, aprendizagem e discurso em sala de aula: aproximações ao estudo do discurso educacional. Porto Alegre: Artmed, 1998.

COLL, C.; SÁNCHEZ, E. Presentación. El análisis de la interacción alumno-profesor: líneas de investigación. Revista de Educación, n. 346, p. 15-32, 2008. Disponível em: <http://www. revistaeducacion.mec.es/re346/re346.pdf>. Acesso em: 3 nov. 2014.

DANIELS, H. Pedagogic practices, tacit knowledge and discoursive discrimination: Bernstein and post-Vygotskian research. British Journal of Sociology of Education, n. 4, v. 16, 1995.

DOYLE, W. Academic work. Review of Educational Research, n. 53, p. 159-199, 1983 citado 
por NUTHALL, G. El razonamiento y el aprendizaje del alumno en el aula. In: BIDDLE, B.J.; GOOD, T.L.; GOODSON, I.F. (comp.). La enseñanza y los profesores II: la enseñanza y sus contextos. Barcelona: Paidós, 2000. p. 19-113.

EDWARDS, D.; MERCER, N. El conocimento compartido: El desarrollo de la comprensión em el aula. Barcelona: Paidós, 1994.

GREEN, J. L. Research on teaching as a linguistic process: A state of the art. In: GORDON, E.W. (Ed.). Review of research in education, v. 10. Washington: AERA apud CAZDEN, C.B. El discurso del aula. In: WITTROCK, M.C. (comp.). La investigación de la enseñanza, v. 3. Barcelona: Paidós, 1997, p. 627-709.

HOADLEY, U.; MULLER, J. Códigos, pedagogia e conhecimento: avanços na sociologia da educação bernsteiniana. In: APPLE, M.W.; BALL, S.J.; GANDIN, L.A. Sociologia da educação: análise internacional. Porto Alegre: Penso, 2013. p. 89-98.

KELLY, G. Discourse in science classrooms. In: ABELL, S.K.; LEDERMAN, N.G. (eds.). Handbook of research on science education. New York: Routledge, 2008, p. 443-469.

LEE, O. Science education with English language learners: synthesis and research agenda. Review of Educational Research, n. 4, v. 75, p. 491-521, 2005.

LEMKE, J. Aprender a hablar ciencia: lenguaje, aprendizaje y valores. Barcelona: Paidós, 1997.

LOPES, J.B. et al. Investigação sobre a mediação de professores de ciências físicas em sala de aula. Vila Real: Universidade de Trás-os-Montes e Alto Douro, 2010.

LOUCA, L.; ZACHARIA, Z.; TZIALLI, D. Identification, interpretation-evaluation, response: an alternative framework for analyzing teacher discourse in science. International Journal of Science Education, n. 12, v. 34, 2012. p. 1823-1856.

MAINARDES, J.; STREMEL, S. A teoria de Basil Bernstein e algumas de suas contribuições para as pesquisas sobre políticas educacionais e curriculares. Teias, n. 22, v. 11, 2010. Disponível em:<http://ri.uepg.br:8080/riuepg/bitstream/handle /123456789/243/ARTIGO_TeoriaBasilBernstein.pdf?sequence=1f $>$. Acesso em: 28 maio 2014.

MORAIS, A.M.; NEVES, I. "Pedagogic social contexts: studies for a sociology of learning". In: MORAIS, A.M. et al. (eds.). Towards a sociology of pedagogy: the contribution of Basil Bernstein to research. New York: Peter Lang, 2001. p. 185-221.

MORTIMER, E. et al. Uma metodologia para caracterizar os gêneros de discurso como tipos de estratégias enunciativas nas aulas de Ciências. In: NARDI, R. (org.). A pesquisa em Ensino de Ciências no Brasil: alguns recortes. São Paulo: Escrituras, 2007. p. 53-116.

NASCIMENTO, S. A linguagem e a investigação em Educação Científica: uma breve apresentação. In: NARDI, R. (org.). A pesquisa em Ensino de Ciências no Brasil: alguns recortes. São Paulo: Escrituras, 2007. p. 131-142.

NUTHALL, G. El razonamiento y el aprendizaje del alumno en el aula. In: BIDDLE, B.J.; GOOD, T.L.; GOODSON, I.F. (comp.). La enseñanza y los profesores II: la enseñanza y sus contextos. Barcelona: Paidós, 2000. p. 19-113.

PERRENOUD, P. Ofício de aluno e sentido do trabalho escolar. Porto: Porto Editora, 1995.

ROSA, R.T.; VEIT, M.H. Estágio docente: análise de interações sociais em sala de aula. Educação e Realidade, v. 36, n. 1. p. 295-316, 2011. Disponível em: < http://www.redalyc.org/ pdf/3172/317227056016.pdf>. Acesso em: 3 jun. 2014.

SANTOS, B. F. Uma aproximação ao estudo entre a linguagem e o ensino de ciências. In: CHAPANI, D.T.; Silva, J. (orgs.). Debates em educação científica. São Paulo: Escrituras, 2013. p. 107-114.

SANTOS, L.L. Bernstein e o campo educacional: relevância, influências e incompreensões. Cadernos de Pesquisa, São Paulo, n. 120, p. 15-49, 2003. Disponível em: <http://www.scielo.br/pdf/cp/ n120/a04n120.pdf>. Acesso em: 26 maio 2014.

SOUZA, G.M. et al.A pesquisa sobre linguagem e ensino de ciências no Brasil em teses e dissertações (2000-2011). In: Encontro Nacional de Pesquisa em Ensino de Ciências, 9., 2013, Águas de Lindóia. Anais (eletrônicos). Rio de Janeiro: Associação Brasileira de Pesquisadores em Educação em Ciências, 2013. Disponível em: <http://www.nutes.ufrj.br/abrapec/ixenpec/atas/resumos/ 
R1326-1.pdf>. Acesso em: 2 jun. 2014.

SILVA, A.C.; MORTIMER, E.F. Caracterizando estratégias enunciativas em uma sala de aula de química: aspectos teóricos e metodológicos em direção à configuração de um gênero do discurso. Investigações em Ensino de Ciências, Porto Alegre, v. 15, n. 1, p. 121-153, 2010. Disponível em: <http:// www.if.ufrgs.br/ienci/artigos/Artigo_ID231/v15_n1_a2010.pdf>. Acesso em: 27 maio 2014.

\section{Contribuiçoes de cada autor no artigo:}

Bruno Ferreira dos Santos é o coordenador do projeto de pesquisa "Ensino de Química e Interações Discursivas em Diferentes Contextos Sociais" que originou o artigo e orientador de Mestrado de Karina Novaes Santos e Eliana Sardinha da Silva, coautoras do artigo. A coleta dos dados deste artigo e a análise dos mesmos foram conduzidas sob a sua orientação, bem como a escrita deste. Karina Novaes Santos coletou os dados para a confecção deste artigo e colaborou com a análise destes e com a escrita do texto.

Eliana Sardinha da Silva ajudou na transcrição dos dados e colaborou com a análise destes, bem como com a escrita do texto do artigo.

Data Recebimento: 21/07/2014

Data Aprovação: 29/09/2014

Data Versão Final: 04/11/2014

\section{(Endnotes)}

Trabalho realizado com o auxílio financeiro do Conselho Nacional de Desenvolvimento Científico e Tecnológico e da Pró-Reitoria de Pesquisa e Pós-Graduação da Universidade Estadual do Sudoeste da Bahia.

\section{Contato:}

Bruno Ferreira dos Santos

Universidade Estadual do Sudoeste da Bahia. Departamento de Química e Exatas.

Campus de Jequié. Rua José Moreira Sobrinho, S/N, Jequiezinho. Jequié, BA, Brasil.

CEP: 45206-190. Email: bf-santos@uol.com.br 